\title{
E-learning Participation in Higher Education: A Study of Scottish and Croatian Students
}

\author{
Kay I. Penny ${ }^{1}$ and Darko Dukic ${ }^{2}$ \\ ${ }^{1}$ School of Management, Edinburgh Napier University, UK \\ ${ }^{2}$ Department of Physics, Josip Juraj Strossmayer University of Osijek, Croatia
}

\begin{abstract}
E-learning is becoming increasingly important in higher education. Information was gathered on students' usage of e-learning activities in Scotland and in Croatia. An exploratory factor analysis reveals four underlying factors which may be used to classify the different types of e-learning activities, and logistic regression modelling was used to identify which student characteristics were associated with each of the different classifications of e-learning. These findings provide an insight into the different usages of e-learning activities, each of which should be considered individually in terms of design and management of e-learning systems, and in the provision of training for staff and students.
\end{abstract}

Keywords: e-learning participation, information and communication technologies, higher education

\section{Introduction}

E-learning involves the use of information and communication technologies (ICT) to deliver teaching and learning. E-learning can include the use of many ICT technologies [16] and has been defined as learning and teaching facilitated online through network technologies [11]. Christie and Ferdos [4] define e-learning in higher education as a technique to enhance learning and teaching experiences, and as a tool to educate students through digital media, with or without the guidance of their instructors. Elearning can be used to replace traditional faceto-face teaching completely, for example via distance learning, or only partially, for example as an additional teaching tool to be used alongside face-to-face teaching. Accessing learning resources using ICT is fast, flexible and has no geographical barriers [6][20]. E-learning technology also offers individuality of courses which can be adapted to the individual student, independent of time and space [8].

The higher education sectors are actively pursuing the increase of the use of online applications of e-learning by using the internet to enhance education [2]; computers are now used by students from many different societies and backgrounds, and ICT are considered valuable tools to enhance learning in higher education.

It has been shown that participation and engagement is a crucial part of learning [23], hence a key challenge for the development of e-learning is to enhance student participation in their learning [3]. Learner participation can be enhanced by the use of ICT in both faceto-face and e-learning course delivery [12][17]. Hrastinski [14] defined the process of learning as taking part and maintaining relations with others; a complex process of doing, communicating, thinking, feeling and belonging, all of which occur both offline and online. A review of the literature in online learner participation is provided by Hrastinski [15], and a claim that participation and learning are intrinsically interrelated. Hence, in order for learners to take full advantage of their learning opportunity, the participation experience must be worthwhile.

A study was carried out to measure students' access to communication areas and a group area [9] and this was used as a measure of participation. The findings concluded that students who failed in at least one module interacted less often than those who passed all modules. Another study [20] found that students who actively participated in online activities scored better marks 
than those who participated less often. Participation has also been shown to be associated with learner satisfaction [1] and increased retention rates [19]. These studies show that online participation is associated with student achievement, and Vonderwell and Zachariah [22] suggest that online participation is influenced by technology and interface characteristics, content area experience, student roles and information overload.

The aim of this study is to determine which student groups are not making sufficient use of online learning, so that these groups of students may be encouraged to use online activities in order to enhance their learning experience. The objectives are to determine underlying classifications of the different types of e-learning participation, and to investigate which demographic or study-related characteristics are independently associated with these classifications of e-learning participation.

\section{Methods}

A questionnaire survey was designed to gather information on students' experiences and usage of ICT during their university studies. The questionnaire survey was carried out in November 2009 in two universities; Edinburgh Napier University in Scotland, and the Josip Juraj Strossmayer University of Osijek in Croatia and is described previously [18]. The Croatian version of the questionnaire was a paper-based questionnaire, and was distributed across the range of students studying at the Josip Juraj Strossmayer University of Osijek. Participation of students was voluntary, and the survey was anonymous.

The English language version of the questionnaire was distributed to students at Edinburgh Napier University following ethics approval from Edinburgh Napier Business School Ethics Committee All students enrolled for study at Edinburgh Napier University were invited to participate in an online questionnaire administered via SurveyMonkey [21].

At the beginning of the questionnaire, students were asked to provide some demographic information e.g. age, gender, and some details regarding their studies e.g. faculty of study, year of study and type of degree etc. The questionnaire requested demographic information and a section on computer use. The next section on the questionnaire asked students to provide details of how often they used a computer or the internet for various tasks related to their studies e.g. for preparing essays or using particular types of software.

An exploratory factor analysis [10] using the principal components method of extraction, was used to identify underlying classifications or themes representing the different types and usages of e-learning. The factor analysis was used to reduce the data set to a smaller number of factors which comprise multiple e-learning measures which all contribute to the same e-learning construct or theme. The Kaiser-Meyer-Olkin measure of sampling adequacy and Bartlett's test of sphericity were calculated to assess whether a factor analysis of these data was appropriate.

This was followed by logistic regression modelling [13] to determine which student characteristics are associated with regular use of the underlying themes of e-learning participation as determined by the preceding factor analysis.

All statistical analysis was carried out using SPSS version 18 .

\section{Results}

Complete responses were received from 620 students at the University of Osijek and from 450 students at Edinburgh Napier University.

Descriptive statistics for the demographic variables are presented in full in Penny, Dukic and Dukic [18]. The average age of the respondents was slightly higher in Scotland compared to Croatia; the median age was 23 years in Scotland and 21 years in Croatia, and there was a much greater spread of mature students in Scotland, with one quarter of respondents aged over 28 years.

The gender breakdown in the two student samples was similar; $63.3 \%$ of respondents in Scotland were female and $57.9 \%$ of respondents in Croatia were female.

A higher proportion of respondents in Scotland were studying for postgraduate degrees (19.8\%), compared to only $0.5 \%$ of respondents studying for postgraduates degrees in Croatia. Of those studying for undergraduate degrees, similar proportions were studying in years one to four in both Scotland and Croatia.

The majority of students in both countries $(98.4 \%$ in Scotland and 99.2\% in Croatia) reported that 
they had unlimited use of a computer or laptop at home, and a slightly higher proportion of students in Scotland have internet access at home $(97.3 \%)$ compared to students in Croatia $(93.4 \%)$.

Respondents were asked to rate how often they used a computer for each activity on a five-point scale labelled: never, occasionally, sometimes, quite often and regularly. Scottish students reported more regular use of the activities except for preparing presentations and contacting fellow students (Table 1).

\begin{tabular}{c|c|c|}
\cline { 2 - 3 } & $\begin{array}{c}\text { Edinburgh } \\
\text { Napier } \\
\text { University } \\
\text { (Scotland) }\end{array}$ & $\begin{array}{c}\text { Josip Juraj } \\
\text { Strossmayer } \\
\text { University } \\
\text { of Osijek } \\
\text { (Croatia) }\end{array}$ \\
\cline { 2 - 3 } & \multicolumn{2}{|c|}{ \% regular use } \\
\hline \hline Computer use: & & \\
Essays & $70.6 \%$ & $48.3 \%$ \\
Presentations & $40.4 \%$ & $42.5 \%$ \\
Reading & $49.6 \%$ & $25.6 \%$ \\
Drawing & $11.6 \%$ & $8.8 \%$ \\
Spreadsheet & $17.7 \%$ & $5.8 \%$ \\
Statistics/maths & $8.6 \%$ & $4.5 \%$ \\
Image/video & $14.1 \%$ & $13.3 \%$ \\
\hline Internet use: & & \\
Contact & $30.5 \%$ & $11.7 \%$ \\
lecturers & $22.4 \%$ & $32.3 \%$ \\
Contact \\
students & $38.0 \%$ & $38.4 \%$ \\
Dept webpages & Download \\
dept materials & $74.2 \%$ & $29.5 \%$ \\
Additional \\
materials & $58.4 \%$ & $29.3 \%$ \\
Submit \\
coursework & $34.1 \%$ & $21.9 \%$ \\
$\begin{array}{c}\text { Online } \\
\text { discussion }\end{array}$ & $10.0 \%$ & $9.9 \%$ \\
Study-related \\
information & $24.1 \%$ & $13.6 \%$ \\
\hline
\end{tabular}

Table 1. Participation in study activities.

A factor analysis was carried out on the fifteen e-learning participation scores (as listed in Table 1) to determine underlying themes or factors which make up the overall student participation in educational usage of ICT applications. The Kaiser-Meyer-Olkin measure of sampling adequacy $(0.838)$ indicates that a factor analysis is appropriate, and Bartlett's test of sphericity indicates that the correlation matrix is not equal to the identity matrix $(\mathrm{p}<0.001)$, suggesting that the strength of the relationship among variables is strong, confirming that factor analysis is appropriate. Four factors, each with an eigenvalue greater than one, were extracted using the principal component method, followed by varimax rotation to aid interpretation of the components. These four factors explained a total of $59.0 \%$ of the variability in scores, and can be explained as factors relating to participation in (1) information and communication, (2) specialised computer software packages, (3) accessing educational information and (4) preparing essays and presentations.

The factor loadings are presented in Table 2. Factor 1 can be interpreted as participation in information and communication technologies in connection with university studies, and has high loadings for contacting students, submitting assessments, searching for departmental and study-related information and participating in online discussions. Factor 2 represents the use of specialised software for drawing or constructing, processing images or video, using statistical or mathematical software, or a spreadsheet. Factor 3 represents accessing educational information such as downloading or reading online teaching materials and contacting lecturers. Factor 4 represents writing essays and reports and preparing presentations.

\begin{tabular}{|c|c|c|c|c|}
\hline \multirow{2}{*}{ Components } & \multicolumn{4}{|c|}{ Factor } \\
\hline & 1 & 2 & 3 & 4 \\
\hline \multicolumn{5}{|l|}{ Computer use: } \\
\hline Essays & 0.069 & 0.014 & 0.389 & 0.753 \\
\hline Presentations & 0.146 & 0.229 & 0.054 & 0.839 \\
\hline Reading & 0.057 & 0.189 & 0.616 & 0.413 \\
\hline Drawing & 0.010 & 0.767 & 0.027 & 0.134 \\
\hline Spreadsheet & -0.012 & 0.774 & 0.321 & 0.044 \\
\hline Statistics/maths & 0.108 & 0.763 & 0.085 & -0.007 \\
\hline Image/video & 0.268 & 0.639 & -0.076 & 0.183 \\
\hline \multicolumn{5}{|l|}{ Internet use: } \\
\hline Contact lecturers & 0.405 & 0.175 & 0.453 & 0.311 \\
\hline Contact students & 0.659 & 0.080 & -0.103 & 0.385 \\
\hline Dept webpages & 0.535 & -0.019 & 0.344 & 0.068 \\
\hline $\begin{array}{l}\text { Download } \\
\text { dept materials }\end{array}$ & 0.269 & 0.126 & 0.755 & -0.001 \\
\hline $\begin{array}{l}\text { Additional } \\
\text { materials }\end{array}$ & 0.248 & 0.009 & 0.757 & 0.127 \\
\hline $\begin{array}{l}\text { Submit } \\
\text { coursework }\end{array}$ & 0.560 & 0.046 & 0.301 & 0.171 \\
\hline $\begin{array}{l}\text { Online } \\
\text { discussion }\end{array}$ & 0.738 & 0.115 & 0.119 & -0.155 \\
\hline $\begin{array}{l}\text { Study-related } \\
\text { information }\end{array}$ & 0.620 & 0.144 & 0.239 & 0.087 \\
\hline
\end{tabular}

Table 2. Factor loadings. 
Logistic regression modelling is used to investigate which student characteristics are associated with regular use of (1) information and communication, (2) specialised software, (3) accessing educational information and (4) preparing essays and presentations. The dependent variable is the factor score which has been converted to a binary scale coded as 0 if the score was less than 0 , and coded as 1 if the score was greater than or equal to 0 , representing regular use of the corresponding factor theme. Since the factor scores were standardised to have mean 0 , this categorisation ensures roughly equal numbers of students in each of the two categories.

Dependent factors which are considered for inclusion in the models are age group, gender, whether studying at undergraduate or postgraduate level, university attended, and faculty of study. The faculties of study are not the same in the two universities; hence some faculties were combined to create similar groups of subject areas. Engineering, physics, computing and creative industries form the ENG faculty group; the LIFE faculty contains health, life, social and philosophical studies and BUS contains business studies and teacher education.

Students aged 23 years or over, or studying health, life, social or philosophical subjects were more likely to participate regularly in the use of ICT for information and communication purposes (Table 3). However, an interaction effect between country and faculty shows that although BUS students were less likely to participate in information and communication use than LIFE students, Croatian BUS students were more likely to participate than LIFE students.

The results in Table 4 show that male students were more likely than females $(\mathrm{OR}=1.8)$ to use specialised software for designing, drawing, mathematics or statistics, as were students in Croatia and students in the ENG faculty.

For using ICT for acquiring educational information, only one variable was significant in the modelling; students in Croatia were far less likely to participate in this use $(\mathrm{p}<0.001)$ than Scottish students $(\mathrm{OR}=0.08,95 \% \mathrm{CI}=0.06$ to 0.1 ). For writing essays and preparing presentations, only the variable gender was significant in the model $(\mathrm{p}<0.001)$. Male students were less likely than females to make use of ICT for writing essays and presentations $(\mathrm{OR}=0.6$, $95 \% \mathrm{CI}=0.5$ to 0.8 ).

\begin{tabular}{|l|c|c|}
\hline & OR (95\% CI) & p-value \\
\hline \hline Age: & & \\
20 years or under & & 0.015 \\
21-22 years & $1.3(0.9,1.7)$ & 0.158 \\
23 years or over & $1.6(1.2,2.2)$ & 0.004 \\
\hline Country: & & \\
Scotland & & \\
Croatia & $1.3(0.8,2.1)$ & 0.259 \\
\hline Faculty: & & \\
ENG & $2.0(1.2,3.2)$ & 0.006 \\
LIFE & $0.8(0.5,1.3)$ & 0.404 \\
BUS & & \\
\hline Interaction term: & & \\
Country * Faculty & & 0.002 \\
Scotland * ENG & & 0.398 \\
Croatia * LIFE & $0.8(0.4,1.4)$ & 0.001 \\
Croatia * BUS & $2.2(1.2,4.0)$ & 0.013 \\
\hline Constant & 0.5 & 0.001 \\
\hline
\end{tabular}

Table 3. Participation in information and communication.

\begin{tabular}{|l|c|c|}
\hline & OR (95\% CI) & p-value \\
\hline \hline Gender: & & \\
Female & & \\
Male & $1.8(1.3,2.3)$ & $<0.001$ \\
\hline Country: & & \\
Scotland & & \\
Croatia & $1.5(0.9,2.4)$ & 0.101 \\
\hline Faculty: & & \\
ENG & & 0.04 \\
LIFE & $0.4(0.3,0.7)$ & 0.001 \\
BUS & $0.6(0.4,0.9)$ & 0.028 \\
\hline Interaction term: & & \\
Country * Faculty & & $<0.001$ \\
Scotland * ENG & & 0.001 \\
Croatia * LIFE & $0.3(0.2,0.6)$ & $<0.001$ \\
Croatia * BUS & $0.3(0.2,0.6)$ & $<.533$ \\
\hline Constant & 1.1 & 0.1 \\
\hline
\end{tabular}

Table 4. Use of specialised software.

\section{Conclusions}

The results presented in this paper confirm that differences exist between students in their participation in the different usages of e-learning activities. The exploratory factor analysis revealed four underlying factors which represent the overall student participation in computer and 
internet use for educational purposes. Although these four factors account for only $59.0 \%$ of the variation in the data, this technique enabled 15 individual study activities to be reduced to four distinct factors, each of which contains a collection of related activities. Hrastinski [15] states that online learner participation includes doing and belonging, and emphasises that students learn both online and offline. The factors determined in this study confirm that e-learning should not be measured by one type of activity alone, and should be viewed as different themes of participation, namely, information and communication, the use of specialised software, accessing educational information and preparing essays and presentations.

Logistic regression modelling was used to determine which student characteristics were associated with regular participation of each of the four distinct factors obtained in the preceding factor analysis. Students aged 23 years or over, or studying health, life, social or philosophical subjects were more likely to participate regularly in the use of ICT for information and communication purposes. However, in Croatia, students studying these subjects were less likely to participate than business students. Male students were more likely than females to use specialised softwares for designing, drawing, mathematics or statistics, as were students in Croatia and students studying engineering, physics, computing and creative industries. Scottish students were more likely than Croatian students to use ICT for acquiring educational information, and females were more likely than males to participate in writing essays and preparing presentations. Previous studies have also found that women are more suited to e-learning activities [7].

The findings presented in this study are based on samples of students from two universities, one in Scotland and one in Croatia, and are therefore subject to sampling variability. However, each sample includes respondents from a range of ages, both genders and different areas of study. Hence the samples are believed to be representative of the two student populations.

It is proposed that all of these e-learning activities in higher education can be incorporated into one of the four themes as determined by the factor analysis. Providers and teachers of higher education may find it useful to consider each of these four themes of e-learning on an individual basis when designing or developing ICT systems, and also when considering the training needs of both staff and students.

It has previously been shown that students who participate in online activities are more likely to be higher achievers educationally [9][20]. The findings in this current study will aid in targeting resources to increase student participation in those groups who participate less regularly in e-learning activities, with an aim to enhancing student engagement and educational achievement.

\section{Acknowledgments}

We wish to thank all students who completed the survey for their time and for providing information regarding their e-learning participation.

\section{References}

[1] M. Alavi, D. DufNer, Technology-mediated collaborative learning: A research perspective. In Learning together online: Research on asynchronous learning networks (S. R. HILTZ, R. GOLDMAN, ED.), (2005) pp. 191-213. Mahwah, NJ, Lawrence Erlbaum.

[2] P. ARABAS, M. B. BAKER, Evolving Campus Support Models for E-learning Courses. ECAR Educause Center for Applied Research, 2003.

http://www .educause.edu/ir/library/pdf / ecar_ so/ers/ERS0303/EKF0303.pdf [05/12/2011]

[3] R. Bento, C. Schuster, Participation: The online challenge. In Web-based education: Learning from experience (A. AgGaRWAL, ED.), (2003) pp. 156-64. Hershey, PA: Idea Group Publishing.

[4] M. F. Christie, F. Ferdos, The mutual impact of educational and information technologies: Building a pedagogy of E-learning. Journal of Information Technology Impact, 4(1) (2004), 15-26.

[5] G. Cohen, I. SAlomon, P. NiJKAmP, InformationCommunications Technologies (ICT) and Transport: Does Knowledge Underpin Policy? Telecommunications Policy, 26(1-2) (2002), 31-52.

[6] F. Concannon, A. Flynn, M. Campbell, What Campus-based students think about the quality and benefits of E-learning. British Journal of Educational Technology, 36(3) (2005), 501-12.

[7] M. Cuadrado-Garcia, M. Ruiz-Molina, J. D. MONTORO-PONS, Are there gender differences in e-learning use and assessment? Evidence from an interuniversity online project in Europe. Procedia Social and Behavioural Sciences, 2 (2010), 367-371. 
[8] C. DAlsGAARD, Pedagogical quality in e-learning: Designing e-learning from a learning theoretical approach. E-learning and Education, 2008. http://eleed.campussource.de/archive/1/ 78 [05/12/11]

[9] J. DAVIES, M. O. GRAFF, Performance in e-learning: Online participation and student grades. British Journal of Educational technology, 36(4) (2005), 657-663.

[10] B. S. EVERITT, G. DunN, Applied multivariate data analysis, $2^{\text {nd }}$ edition. Arnold, London, 2001.

[11] D. R. GARRISON, T. ANDERSON, E-learning in the $21^{\text {st }}$ century: A framework for research and practice. Routledge Farmer, London, 2003.

[12] C. HAYTHORNTHWAITE, Building social networks via computer networks: Creating and sustaining distributed learning communities. In Building Virtual communities: Learning and change in cyberspace (K. RENNINGER, W. SCHUMER, ED.), (2002) pp. 159-190. Cambridge University Press, Cambridge.

[13] D. W. Hosmer, S. Lemeshow, Applied Logistic Regression, $2^{\text {nd }}$ edition. John Wiley \& Sons, USA, 2000.

[14] S. HRASTINSKI, What is online learner participation? A literature review. Computers \& Education, 51 (2008), 1755-1765.

[15] S. HRASTINSKI, A theory of online learning as online participation. Computers \& Education, 52(1) (2009), 78-82.

[16] E. K. Kahitgi, L. Ekenberg, H. Hansson, F. F. TUSUBIRA, M. DANIELSON, Exploring the e-learning state of art. The Electronic Journal of e-learning, 6(2) (2008), 77-88.

[17] D. E. LEIDNER, S. L. JARVENPAA, The use of information technology to enhance management school education: A theoretical view. MIS Quarterly, 19(3) (1995), 265-291.

[18] K. I. PenNy, G. DuKIC, D. DuKIC, Knowledge Management: Information and Communication Technologies Usage in Scottish and Croatian Students. In Proceedings of the $32^{\text {nd }}$ International Conference on Information Technology Interfaces (V. LUZARSTIFFLER, I. JAREC, Z. BEKIC, ED.), (2010 Jun 2124), Cavtat, Croatia. Zagreb: SRCE University Computing Centre, University of Zagreb, (2010), pp. 385-390.

[19] A. RovAI, Building sense of community at a distance. International review of research in open and distance learning, 3(1) (2001), 1-16.
[20] S. Sivapalan, P. CREGAN, Value of online resources for learning by distance education. CAL-laborate, 14 (2005), 23-27.

[21] SURVEYMONKEY.COM, 2011. http://www.surveymonkey.com [05/12/11]

[22] S. VONDERWELL, S. ZACHARIAH, Factors that influence participation in online learning. Journal of Research on Technology in Education, 38(2) (2005), 213-230.

[23] E. Wenger, Communities of practice: Learning, meaning, and identity. Cambridge University Press, Cambridge, 1998.

Received: June, 2012 Accepted: August, 2012

Contact addresses: Kay Penny School of Management Edinburgh Napier University Craiglockhart Campus Edinburgh, EH14 1DJ

e-mail: k.penny@napier.ac.uk

Darko Dukić

Department of Physics Josip Juraj Strossmayer University of Osijek Trg Ljudevita Gaja 6, 31000 Osijek

e-mail: darko.dukic@fizika.unios.hr

KAY PENNY studied at the University of Aberdeen, Scotland at both undergraduate and postgraduate levels, and was awarded a PhD in 1995. Since 1999, she has held the post of Lecturer at Edinburgh Napier University in Edinburgh, Scotland, and had previously held posts at the University of Aberdeen (1995 - 1997) and Edinburgh University (1997 - 1999). Her research interests include applied statistics, survey methods, technology-enhanced learning, data-mining and missing data imputation methods.

DARKO DUKIĆ is an Assistant Professor in the field of information and communication sciences in the Department of Physics at the Josip Juraj Strossmayer University of Osijek, Croatia. He received his M.Sc. and $\mathrm{Ph} . \mathrm{D}$. degrees from the same University. He is author or coauthor of more than 50 scientific papers published in international journals and presented at international conferences. In addition, he has reviewed many articles for scientific journals and conferences, and chaired thematic sessions at various meetings. Over the past few years he has worked on several scientific research projects. His research interests include information technology implementation and adoption, e-learning, management information systems, simulation models, statistics and data mining. 